\title{
DItX of Bacillus thuringiensis Is Essential for D-Alanylation of Teichoic Acids and Resistance to Antimicrobial Response in Insects
}

OPEN ACCESS

Edited by:

Bart Devreese

Ghent University, Belgium

Reviewed by:

Guy Condemine,

UMR5240 Microbiologie, Adaptation et Pathogenie (MAP), France

Gong-Yin Ye,

Zhejiang University, China

*Correspondence:

Vincent Sanchis-Borja vincent.sanchis-borja@inra.fr

Specialty section: This article was submitted to Antimicrobials, Resistance

and Chemotherapy,

a section of the journal

Frontiers in Microbiology

Received: 13 April 2017

Accepted: 14 July 2017

Published: 03 August 2017

Citation:

Kamar R, Réjasse A, Jéhanno I,

Attieh $Z$, Courtin $P$,

Chapot-Chartier M-P

Nielsen-Leroux C, Lereclus $D$,

el Chamy L, Kallassy M and

Sanchis-Borja V (2017) DltX

of Bacillus thuringiensis Is Essential

for D-Alanylation of Teichoic Acids and Resistance to Antimicrobial

Response in Insects.

Front. Microbiol. 8:1437.

doi: 10.3389/fmicb.2017.01437
Rita Kamar1,2,3, Agnès Réjasse 1,2, Isabelle Jéhanno ${ }^{1,2}$, Zaynoun Attieh ${ }^{3}$, Pascal Courtin ${ }^{1,2}$, Marie-Pierre Chapot-Chartier ${ }^{1,2}$, Christina Nielsen-Leroux ${ }^{1,2}$, Didier Lereclus ${ }^{1,2}$, Laure el Chamy ${ }^{3}$, Mireille Kallassy ${ }^{3}$ and Vincent Sanchis-Borja ${ }^{1,2 *}$

'INRA, UMR1319 Micalis, Jouy-en-Josas, France, ${ }^{2}$ AgroParisTech, UMR Micalis, Jouy-en-Josas, France, ${ }^{3}$ Laboratoire de Génétique de la Drosophile et Virulence Microbienne, Université Saint-Joseph, Beirut, Lebanon

The dlt operon of Gram-positive bacteria is required for the incorporation of D-alanine esters into cell wall-associated teichoic acids (TAs). Addition of D-alanine to TAs reduces the negative charge of the cell envelope thereby preventing cationic antimicrobial peptides (CAMPs) from reaching their target of action on the bacterial surface. In most gram-positive bacteria, this operon consists of five genes dltXABCD but the involvement of the first ORF (dlt X) encoding a small protein of unknown function, has never been investigated. The aim of this study was to establish whether this protein is involved in the D-alanylation process in Bacillus thuringiensis. We, therefore constructed an in frame deletion mutant of $d l t X$, without affecting the expression of the other genes of the operon. The growth characteristics of the $d l t X$ mutant and those of the wild type strain were similar under standard in vitro conditions. However, disruption of dltX drastically impaired the resistance of $B$. thuringiensis to CAMPs and significantly attenuated its virulence in two insect species. Moreover, high-performance liquid chromatography studies showed that the dltX mutant was devoid of D-alanine, and electrophoretic mobility measurements indicated that the cells carried a higher negative surface charge. Scanning electron microscopy experiments showed morphological alterations of these mutant bacteria, suggesting that depletion of D-alanine from TAs affects cell wall structure. Our findings suggest that DItX is essential for the incorporation of D-alanyl esters into TAs. Therefore, DItX plays a direct role in the resistance to CAMPs, thus contributing to the survival of $B$. thuringiensis in insects. To our knowledge, this work is the first report examining the involvement of $d l t X$ in the D-alanylation of TAs.

Keywords: B. thuringiensis, dltX, antimicrobial peptides, virulence, D-alanylation, insects, innate immunity

\section{INTRODUCTION}

The cell wall of gram-positive bacteria contains highly charged anionic polymers called teichoic acids (TAs) that consist of alditol phosphate repeats. These polymers are either anchored to the cytoplasmic membrane via a lipid anchor [lipoteichoic acid (LTA)] (Fischer, 1988; Fischer et al., 1990) or covalently linked to $N$-acetylmuramic acid residues of the peptidoglycan layer 
[wall teichoic acid (WTA)] (Xia et al., 2010; Brown et al., 2013). The best characterized structures of WTA are poly(glycerolphosphate) and poly(ribitolphosphate) found in Bacillus subtilis and Staphylococcus aureus respectively (Fischer and Rösel, 1980; Reichmann and Gründling, 2011). Regarding LTA, the most common structure is poly(glycerolphosphate) (Schneewind and Missiakas, 2014). The function of TAs is not fully understood; they have long been considered to be essential for Gram-positive bacteria. However, this is no longer the case since mutants of $S$. aureus or B. subtilis devoided of WTA have been obtained (D'Elia et al., 2006a,b). Nevertheless, they play crucial roles in cell morphology and division and are important for many cell envelope-dependent processes such as the activity of autolytic enzymes, the binding of divalent cations, and susceptibility to innate host defenses (Weidenmaier and Peschel, 2008). WTAs and LTAs can be covalently modified by substitutions with either glycosyl residues or D-alanyl esters, or both (Fischer and Rösel, 1980; Fischer et al., 1990). The high prevalence of D-alanylation among Gram-positive species suggests that D-alanylation of TAs is biologically relevant, especially for pathogenic bacteria in the context of host-pathogen relationship (Abachin et al., 2002; Chan et al., 2007). Indeed, covalent addition of cationic molecules such as D-alanine allows bacteria to adjust their net negative charge leading to the repulsion of positively charged host immune factors such as cationic antimicrobial peptides (CAMPs) (Peschel, 2002; Nizet, 2006). CAMPs are positively charged antimicrobial molecules that participate in the first line of defense of a wide variety of organisms ranging from prokaryotes to mammals (Nguyen et al., 2011). CAMPs, that also have hydrophobic domains, are electrostatically attracted by the negatively charged surface of the microbial cell envelope, where they get embedded into the hydrophobic regions of the lipid membranes, thereby causing membrane damage and ultimately leading to cell death (Yount and Yeaman, 2013). CAMPs, such as cecropin, defensin, and defensin-like peptides, are present at all sites in the human body that are routinely exposed to microbes (skin, mucosae, neutrophils, eosinophils, and platelets). Consequently, many pathogens have developed resistance strategies involving the reduction of the cell envelope negative charge, thereby decreasing electrostatic interactions between CAMPs and the negatively charged TAs that are key components of their cell envelope (Schneewind and Missiakas, 2014). The incorporation of D-alanine esters into TAs to partially neutralize the negative charge of their cell walls represents one of the most common bacterial resistance mechanisms that depend on such charge modifications (Fischer, 1994; Collins et al., 2002; Poyart et al., 2003; Kovács et al., 2006; Abi Khattar et al., 2009; McBride and Sonenshein, 2011).

The process of D-alanylation is accomplished by the gene products of an operon containing four to five genes, $\operatorname{dlt}(X) A B C D$, that is highly conserved among nearly all gram-positive bacteria (Perego et al., 1995; Neuhaus et al., 1996). These genes have also been found in a few Gram-negative bacteria, notably in soft-rot plant pathogenic enterobacteria (Dickeya and Pectobacterium spp.), where they have been shown to confer resistance to AMPs, probably by modifying the surface lipopolysaccharides (LPSs)
(Pandin et al., 2016). DltA is a D-alanine-D-alanyl carrier protein ligase that catalyzes the D-alanylation of the D-alanyl carrier protein DltC (Heaton and Neuhaus, 1992, 1994; Debabov et al., 1996). The roles of DltB and DltD are less clear. Two models have been proposed: according to Neuhaus and Baddiley, DltD is thought to facilitate $\mathrm{D}$-alanine ligation to DltC and DltB is believed to be involved in the translocation of AlanylatedDltC across the membrane where it may then transfer D-alanine directly onto LTA (Debabov et al., 2000; Neuhaus and Baddiley, 2003). A second model has been proposed, by Fisher and colleagues, to account for the contributions of DltB and DltD; in this model DltB transfers D-alanine from DltC to undecaprenylphosphate $\left(\mathrm{C}_{55}-\mathrm{P}\right)$ to produce D-Ala-P-C $\mathrm{C}_{55}$. This lipid linked intermediate is, then, flipped across the membrane, whereas DltD, active at the outer side of the membrane, transfers D-Ala to LTA (Fischer, 1994). Reichmann et al. (2013) recently reexamined the function of the dlt operon and found that DltC does not pass through the membrane and, therefore, that it is unlikely that this protein is involved in the final D-alanylation step of LTAs. They also showed that DltD is targeted to the outside of the cell as was suggested by Fisher and colleagues in their model. Nevertheless, the existence of a D-Ala-P-C ${ }_{55}$ lipid linked intermediate has never been confirmed experimentally. In Dickeya dadantii, the dltB mutant is more sensitive to antimicrobial peptides than the wild type (WT) strain, but a dltD mutant is as resistant as the WT strain (Pandin et al., 2016).

Mutants with TAs lacking D-alanine esters exhibit a variety of phenotypic changes. For example, mutants of S. aureus lacking a functional $d l t$ operon are deficient in their ability to regulate the anionic charge of the outer envelope and show poor survival both when they are exposed to CAMPs in vitro and when they are introduced to a host in vivo (Peschel et al., 1999). Similarly, mutants of the intracellular pathogen Listeria monocytogenes lacking functional $d l t A$ are highly susceptible to CAMPs (Abachin et al., 2002). B. subtilis also uses dlt to modify TAs, and thus reduce its sensitivity to CAMPs (Perego et al., 1995). In Bacillus anthracis, the dlt genes are turned on during spore germination in the host and are necessary for resistance to innate host defenses (Fisher et al., 2006). We have also previously shown that a Bacillus cereus mutant lacking a functional dlt operon is highly sensitive to colistin and polymyxin B, two standard antimicrobial compounds that have long been used to define the mechanisms by which CAMPs kill bacteria. Virulence of this mutant in an insect model was also significantly attenuated (Abi Khattar et al., 2009).

The dlt operon has been studied in many organisms and inactivation of any single gene ( $d l t A$ to $d l t D$ ) is enough to completely abrogate operon function (Peschel et al., 1999; Collins et al., 2002; Vélez et al., 2007; Abi Khattar et al., 2009). In $B$. subtilis, each gene of the dltABCD operon is required for the D-alanylation of LTA and these four proteins are believed to be the only proteins that are necessary and sufficient for D-Ala incorporation (Perego et al., 1995). However, in B. subtilis, as in most gram-positive bacteria, the operon contains a fifth gene encoding a small protein of less than 50 amino acids in length, DltX. Wang et al. (2004) using a mathematical algorithm have predicted that this small ORF upstream from $d l t A$ is part 
TABLE 1 | Primer sequences used in this study.

\begin{tabular}{ll}
\hline Oligo name & Nucleotide sequence $\left(\mathbf{5}^{\prime} \mathbf{-} \mathbf{3}^{\prime} \mathbf{)}\right.$ \\
\hline dltX-a & CATGCCATGGTCGCAATTACTTCCCTTC \\
dltX-b & CAATTGTTCTAATAACTTCATGTCTTCCCTCTCTTAATG \\
dltX-c & CATTAAGAGAGGGAAAGACATGAAGTTATAGAACAAATTG \\
dltX-d & GAAGATCTACGCTTGGACCGACAATTAC \\
Comp-F & GCTCTAGAAATGCCTTCTCCATTCACG \\
Comp-R & CCCCCCGGGGTCTTGCGGACTAGTTGG \\
Xbal-dlt-gfp & CGTCTAGAACCCATTGTGTGAGTGTCG \\
EcoRI-dlt-gfp & CGGAATCACCCATTACAAATCATGCTG \\
BCF1372.Q3 & AATTGAAAAGTGGCTGCAGAA \\
BCR1372.Q3 & CGCATCTCGCCAAACAAAA
\end{tabular}

*Restriction sites are underlined.

of the $d l t$ operon and several experimental analyses, in several species, have shown that, all five genes of the operon belong to the same transcriptional unit (Koprivnjak et al., 2006; Palumbo et al., 2006; Bron et al., 2012). Nevertheless, despite being encoded upstream of $d l t A$ in several gram-positive bacteria, the role of DltX in TAs D-alanylation has not yet been investigated. Therefore, the aim of this study was to determine whether $d l t X$ encodes a novel protein with a role in D-alanylation of TAs. We therefore constructed a $\Delta d l t X$ mutant strain in Bacillus thuringiensis strain 407 (Bt 407), by allelic replacement, without affecting the expression of the other four genes of the operon. We then analyzed the effect of the deletion on the morphological and physicochemical properties of the bacterial surface, and examined its effects on bacterial virulence and resistance to host immunity. We report here that the $d l t X$ of $B$. thuringiensis is essential for the incorporation of D-alanyl esters into TAs and is required for resistance to CAMPs and for full virulence of the bacterium following its injection into the model insects Galleria mellonella and Drosophila melanogaster.

\section{MATERIALS AND METHODS}

\section{Bacterial Strains and Growth Conditions}

The acrystalliferous strain B. thuringiensis 407 Cry- belonging to serotype 1 (Lereclus et al., 1989) was used throughout this study and designated as Bt 407. Escherichia coli K-12 strain TG1 was used for the construction of plasmids and cloning experiments, and E. coli ET 12567 Dam- Dcm- (Stratagene, La Jolla, CA, United States) was used to generate unmethylated DNA for the electrotransformation of Bt 407. E. coli and Bt 407 cells were transformed by electroporation as previously described (Dower et al., 1988; Lereclus et al., 1989). Bacillus strains were grown at $30^{\circ} \mathrm{C}$ in Luria Broth (LB) or in HCT, a sporulation-specific medium (Lecadet et al., 1980). E. coli strains were grown at $37^{\circ} \mathrm{C}$ in LB. For electrotransformation experiments, Bt 407 was grown in brain heart infusion broth (Difco). Media for bacterial selection were supplemented with 50 or $100 \mu \mathrm{g} / \mathrm{mL} \mathrm{X-Gal} \mathrm{(5-}$ bromo-4-chloro-3-indolyl- $\beta$-D-galactopyranoside) for E. coli and B. cereus, respectively, and with $100 \mu \mathrm{g} / \mathrm{mL}$ ampicillin (Amp) for E. coli, and $200 \mu \mathrm{g} / \mathrm{mL}$ kanamycin $(\mathrm{Km})$ or $10 \mu \mathrm{g} / \mathrm{mL}$ erythromycin for B. cereus as needed.

\section{Manipulation of DNA}

Chromosomal DNA was extracted from Bacillus cells harvested in the mid-exponential growth phase, with the GENTRA Puregene DNA Purification bacteria Kit (QIAgen, France). Plasmid DNA was extracted from $E$. coli by a standard alkaline lysis procedure using QIAprep spin columns (QIAgen, France). Restriction enzymes and T4 DNA ligase (New England Biolabs, United States) were used in accordance with the manufacturer's recommendations. Oligonucleotide primers used in this study are listed in Table $\mathbf{1}$ and were synthesized by Sigma-Proligo (Paris, France). PCR was performed in a thermocycler, Applied Biosystems 2720 Thermal cycler (Applied Biosystems, United States). Amplified fragments were purified with the QIAquick PCR purification Kit (QIAgen). Digested DNA fragments were separated on $1 \%$ agarose gels and were extracted from gels with the QIAquick gel extraction Kit (QIAgen). Nucleotide sequences were determined by Beckman Coulter Genomics (Takeley, United Kingdom). Electroporation to transform Bt 407 was carried out as previously described (Lereclus et al., 1989).

\section{Construction of a dltX Deletion Mutant}

A $B$. thuringiensis strain containing a $d l t X$ deletion was generated by precise, in frame allelic exchange and deletion replacement without antibiotic resistance cassettes. The thermosensitive plasmid MAD (pMAD) was used in these experiments. The 846 bp sequence immediately upstream from $d l t X$ was amplified with the primers dltX-a, dltX-b, and a 1064 bp sequence immediately downstream from dltX was amplified with the primers dltX-c and dltX-d. The primers dltX-b and dltX-c introduce overlapping PCR products. The two amplicons were then subjected to another PCR cycle with the primers dlt-a and dlt-d., such that a modified dlt operon, from which 159 bp had been deleted, was amplified. This amplicon was digested with NcoI and BglII and was introduced between the corresponding cloning sites of pMAD. Bt 407 was then transformed with $10 \mu \mathrm{g}$ of the recombinant plasmid by electroporation as previously described (Lereclus et al., 1989). Transformants were subjected to allelic exchange by homologous recombination and bacteria sensitive to erythromycin, resulting from double crossing over event in which the chromosomal $d l t X$ copy was replaced with the overlapping sequences, were selected. The procedure for selection of mutants by allelic exchange via double crossover has been described previously (Bravo et al., 1996). Chromosomal allelic replacement in the $d l t X$ mutant was confirmed by DNA sequencing of the PCR fragments generated from the primer pairs dltX-a and dltX-d, and the resulting $d l t X$-deficient strain was designated $407 \Delta d l t X$.

\section{Complementation of the dltX Mutant}

For the complemented strain, the entire dltX open reading frame of $B t 407$ strain with its promotor region was amplified from genomic DNA of Bt 407 by PCR with Taq DNA polymerase (Extensor High-Fidelity; Thermo Scientific). The forward primer Comp $\mathrm{F}$ included a restriction site for $\mathrm{XbaI}$ and the reverse primer Comp $\mathrm{R}$ included a restriction site for 
XmaI. The resulting $611 \mathrm{~kb}$ fragment was digested with $\mathrm{XbaI}$ and XmaI, gel-purified, and ligated to the pHT304-18 shuttle vector previously digested with the same enzymes. An aliquot of ligation mixture ( $~ 50$ ng DNA) was used to transform E. coli TG1 by

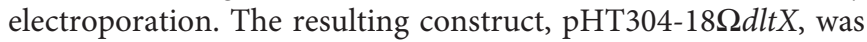
verified by restriction mapping and transferred into $E$. coli ET 12567 by electroporation. Unmethylated plasmid pHT304$18 \Omega$ dltX from E. coli ET 12567 was then introduced into strain Bt $407 \Delta d l t X$ by electroporation.

\section{Construction of Pdlt $\Omega$ gfp Fusion Reporter Plasmid}

The upstream promoter region of the dlt operon (Pdlt) was amplified by PCR with Taq DNA polymerase (New England Biolabs) and with the primer pair XbaI-dlt-gfp and EcoRI-dltgfp (Table 1). The 239 bp PCR product was digested with XbaI and EcoRI, and ligated into the same sites upstream of the

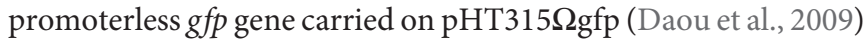

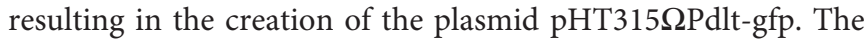
plasmid was verified by restriction analysis, PCR, and sequencing and was transferred into E. coli ET 12567 by electroporation. Unmethylated plasmids from E. coli ET 12567 were then introduced into Bt 407 and Bt $407 \Delta d l t X$ mutant strains by electroporation.

\section{Quantitative RT-qPCR}

The amounts of $d l t A$ transcripts in Bt407 and $\Delta d l t X$ strains were measured by real time reverse transcription. RNA extraction and cDNA synthesis were performed as described previously (Réjasse et al., 2012). Primers BCF1372.Q3 and BCR1372.Q3 located inside the dltA gene were designed with Primer Express software from Applied Biosystems. Real time PCR was carried out with Sybr green PCR master mix (Applied Biosystems) as recommended by the supplier. Mean values were calculated from two separate experiments in which qPCR reactions were performed in triplicate. The cycle threshold was used to determine the relative $d l t A$ gene expression levels in the two genetic backgrounds. Data were analyzed by the comparative threshold cycle $(\Delta \Delta \mathrm{Ct})$ method with the Relative Expression Software Tool (REST 2009 V2.0.13, QIAgen). Expression ratios were normalized to two Bt 407 endogenous reference housekeeping genes, pur and tpi.

\section{Scanning Electron Microscopy (SEM) Analysis}

Scanning electron microscopy (SEM) was performed at the Microscopy and Imaging Platform MIMA2 (Micalis, B2HM, Massy, France) of the INRA research center of Jouy-en-Josas (France). Samples were fixed with $3 \%$ glutaraldehyde in $0.1 \mathrm{M}$ sodium cacodylate buffer at $\mathrm{pH} 7.4$ at room temperature (RT) for $1 \mathrm{~h}$. They were then washed three times for $5 \mathrm{~min}$ with a solution of $0.1 \mathrm{M}$ sodium cacodylate. Samples were progressively dehydrated with increasing concentrations of ethanol $(50 \%-70 \%-90 \%-2 \times 100 \%)$ at RT for $10 \mathrm{~min}$ in each bath, except for $70 \%$ (35 min). Samples were critical point dried at 75 bar and $37^{\circ} \mathrm{C}$ in a Quorum Technologies K850 device
(Elexience, France). Liquid $\mathrm{CO}_{2}$ was used as the transition fluid. Coupons were mounted on aluminum stubs with double-sided sticky tape. Samples were sputter coated in Ar with Pt (30 nm of thickness) in a Polaron SC7640 device (Elexience, France) at $10 \mathrm{~mA}$ and $0.8 \mathrm{kV}$ for $200 \mathrm{~s}$. Observations were performed on a FE-SEM S4500 (Hitachi, Japan) with a sample holder tilted at $45^{\circ}$ and a low SE detector, at $2 \mathrm{kV}$ and $16 \mathrm{~mm}$ WD.

\section{D-alanine Quantification of TAs by High-Performance Liquid Chromatography}

Strains were grown in LB medium to an OD of 2. A volume of $100 \mathrm{~mL}$ of cells was pelleted by centrifugation, washed twice with ammonium acetate buffer (20 mM; pH 4.7), and resuspended in $5 \mathrm{ml}$ of the same buffer. Cells were heatinactivated $\left(10 \mathrm{~min}, 100^{\circ} \mathrm{C}\right)$ and lyophilized. D-alanine was released from whole cells by mild alkaline hydrolysis, as reported previously (Kristian et al., 2005). Mild alkaline hydrolysis was carried out with $10 \mathrm{mg}$ of dried cells at $37^{\circ} \mathrm{C}$ for $1 \mathrm{~h}$ in $150 \mu \mathrm{L}$ $\mathrm{NaOH}$ at $0.1 \mathrm{~N}$. After neutralization with $0.1 \mathrm{~N} \mathrm{HCl}$, the cells were removed by centrifugation and the supernatant was dried under vacuum, and used for precolumn derivatization with Marfey's reagent (1-fluoro-2,4-dinitrophenyl-5-L-alanine amide; Sigma) as described previously (Kochhar and Christen, 1989). Marfey's reagent reacts with the optical isomers of amino acids to form diastereomeric $N$-aryl derivatives that can be separated by high-performance liquid chromatography (HPLC). Amino acid derivatives were separated on a C18 reversed-phase column (Hypersil 100, $250 \mathrm{~mm} \times 4.6 \mathrm{~mm}, 5 \mu \mathrm{m}$, Thermo) at $30^{\circ} \mathrm{C}$ with a Waters HPLC system. Elution was performed with a linear gradient of acetonitrile in sodium acetate buffer $(20 \mathrm{mM}, \mathrm{pH} 4)$ as described previously (Kristian et al., 2005). Absorbance of the eluate was monitored at $340 \mathrm{~nm}$. D-Ala derivatives were identified by their retention time and quantified using an external standard calibration curve.

\section{Electrophoretic Mobility}

Bacteria were suspended in $1.5 \times 10^{-3} \mathrm{M}$ sodium chloride at a concentration of $10^{8} \mathrm{CFU}$ to measure electrophoretic mobility. The $\mathrm{pH}$ of the suspension was adjusted to $\mathrm{pH} 7$ with nitric acid $\left(\mathrm{HNO}_{3}\right)$. Electrophoretic mobility was measured with a $50-\mathrm{V}$ electric field and a Laser Zetameter (Zetaphoremetre II; Societé d'Etude Physico-Chimiques, Limours, France). The results were assessed from an automated video of about 200 particles for each measurement. Each experiment was performed in duplicate with two independently prepared cultures. The typical standard deviation for the electrophoretic mobility mean was $0.25 \times 10^{-8}$ $\mathrm{m}^{2} \mathrm{~s}^{-1} \mathrm{~V}^{-1}$.

\section{In Vivo Pathogenicity Assays Virulence in Galleria mellonella}

Pathogenicity assays were carried out with bacterial vegetative cells (OD $600=1$ ) grown in LB liquid medium and G. mellonella. G. mellonella eggs were hatched at $25^{\circ} \mathrm{C}$ and the larvae were reared on beeswax and pollen (La Ruche Roannaise, Roanne, France). For the infection experiments, the larvae are starved $24 \mathrm{~h}$ 
prior to infection and $10^{4}$ bacterial vegetative cells suspended in $10 \mu \mathrm{l}$ PBS buffer were injected into the hemocoel of last instar G. mellonella larvae (weighing about $200 \mathrm{mg}$ ) with a 0.5 -by- $25 \mathrm{~mm}$ needle and a microinjector (KdScientific syringe pump). The larvae in the control group were injected with PBS buffer. Following inoculation, the larvae were kept by groups of five in small Petri-dishes without food (Bouillaut et al., 2005) and mortality was recorded after $48 \mathrm{~h}$ of incubation at $30^{\circ} \mathrm{C}$. For each strain, 20 larvae were used for toxicity assay and the results shown are the means of at least three independent experiments.

\section{Virulence in Drosophila melanogaster}

The WT Oregon R strain and the relish ${ }^{E 20}$ mutant strain (impaired in IMD signaling and production of antimicrobial peptides) were used in this analysis (Hedengren et al., 1999). Overnight bacterial cultures were washed in PBS and diluted to OD $600=2$. Twenty adult female flies aged between 2 and 5 days were pricked with a thin tungsten needle formerly dipped into the bacterial preparation as previously described (Ligoxygakis et al., 2002). Surviving flies were counted every $2 \mathrm{~h}$.

\section{Minimal Inhibitory Concentrations}

Polymyxin B has long been used to define the mechanisms by which AMPs kill bacteria [46]. Susceptibility to polymyxin B was evaluated by determining the half inhibitory concentration $\left(\mathrm{IC}_{50}\right)$ from dose-response curves obtained with various concentrations of polymyxin B. The tests were performed in 96-well microplates containing 7-9 concentrations (from 200 to $800 \mu \mathrm{g} / \mathrm{ml}$ ) of polymyxin B (Sigma) for WT 407 and $407 \Delta d l t X$ complemented strains, and from 3 to $25 \mu \mathrm{g} / \mathrm{ml}$ for $407 \Delta d l t X$. Bacterial growth was scored after inoculation of strains at an initial $\mathrm{OD}_{600}$ of 0.1 and incubation at $30^{\circ} \mathrm{C}$ for $6 \mathrm{~h}$. $\mathrm{IC}_{50}$ corresponds to the concentration of polymyxin $\mathrm{B}$ required to inhibit inoculum viability by half and was determined as the concentration required to bring the curve down to point half way between its top and bottom plateau. The results shown are the means of at least three independent experiments performed in duplicate.

\section{Statistical Analysis}

Results concerning D-alanine quantification of TAs, electrophoretic mobility and in vivo pathogenicity assays were analyzed by the two-tailed Student's $t$-test. A $p$-value of 0.05 was considered to be significant.

\section{RESULTS}

\section{In Silico Analysis of DItX}

In silico BLAST searches indicate that the dltX gene is present in 809 species of which 805 are Firmicutes, including Bacillus, Staphylococcus, Listeria, Lactobacillus, Streptococcus, and Enterococcus. In most cases, dltX is located immediately upstream from dltA. In $B$. thuringiensis this operon consists of five genes dltXABCD. In strain Bt 407, transcripts of dltX have been detected by mapping RNA-seq datasets, obtained in vitro 2 and $5 \mathrm{~h}$ after the end of exponential phase and in vivo in infected $G$. mellonella cadavers, $36 \mathrm{~h}$ post mortem,

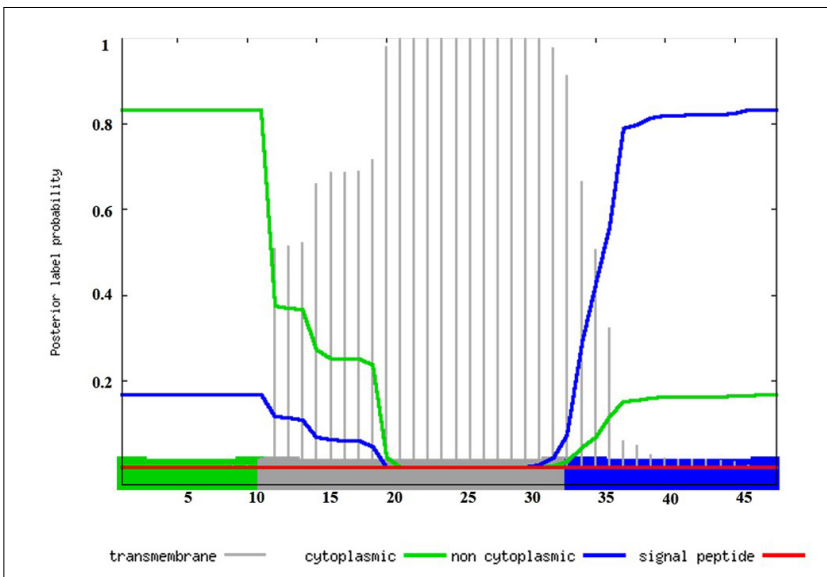

FIGURE 1 | In silico analysis of DItX by Phobius, a combined transmembrane protein topology and signal peptide predictor. Transmembrane, cytoplasmic, and non-cytoplasmic domains are represented in the chart. The plot shows the posterior probabilities of cytoplasmic/non cytoplasmic/TM, helix/signal peptide. Predicted transmembrane (amino acids 12 to 33: LTQWVAKTVYYLAILFALLWLY) regions are shown in gray, cytoplasmic and non-cytoplasmic regions are shown in green and blue respectively (amino acids 1 to 11: MERLKEIWSRP and amino acids 34 to 48:

GFHDTNTSTFIYNEF). The prediction gives the most probable location and orientation of transmembrane helices in the sequence.

with the Bt 407 reference genome (Sébastien Gélis-Jeanvoine, personal communication). These data prompted us to carry out a detailed analysis of the role of this protein in the process of D-alanylation. DltX belongs to the DUF3687 superfamily of proteins. To date, 811 sequences with this domain are listed in Pfam. Proteins in this family are approximately 50 amino acids in length and their protein sequences are highly conserved among the firmicutes. There are two completely conserved residues ( $\mathrm{L}$ and $\mathrm{Y}$, at positions 23 and 45 of the protein, respectively) that may be functionally important. A number of entries are annotated as D-Ala-teichoic acid biosynthesis protein; however, there is no direct evidence to support this annotation. In Bt 407, DltX contains 11 positively charged amino groups clustered near the N-terminus followed by a hydrophobic region of 22 amino acids and by a putative non-cytoplasmic domain of 15 amino acids in the C-terminus. The 22 amino acids hydrophobic region is predicted to form an $\alpha$-helix, which suggests that DltX is a transmembrane protein. The topology of DltX present in the Gram negative species is the same, although there is no sequence similarity. In addition, DltX does not have a predicted signal peptide, which suggests that it is probably not exported (Figure 1).

\section{Deletion of dltX Does Not Affect the Expression of the dit Operon}

We sought to study the influence of dltX on teichoic acid $\mathrm{D}$-alanylation; therefore, we constructed a mutant harboring a precise in frame allelic deletion of the B. thuringiensis dltX gene, to avoid impact on the transcription of the downstream located $d l t$ genes. We used the overlap extension (OE-PCR) 


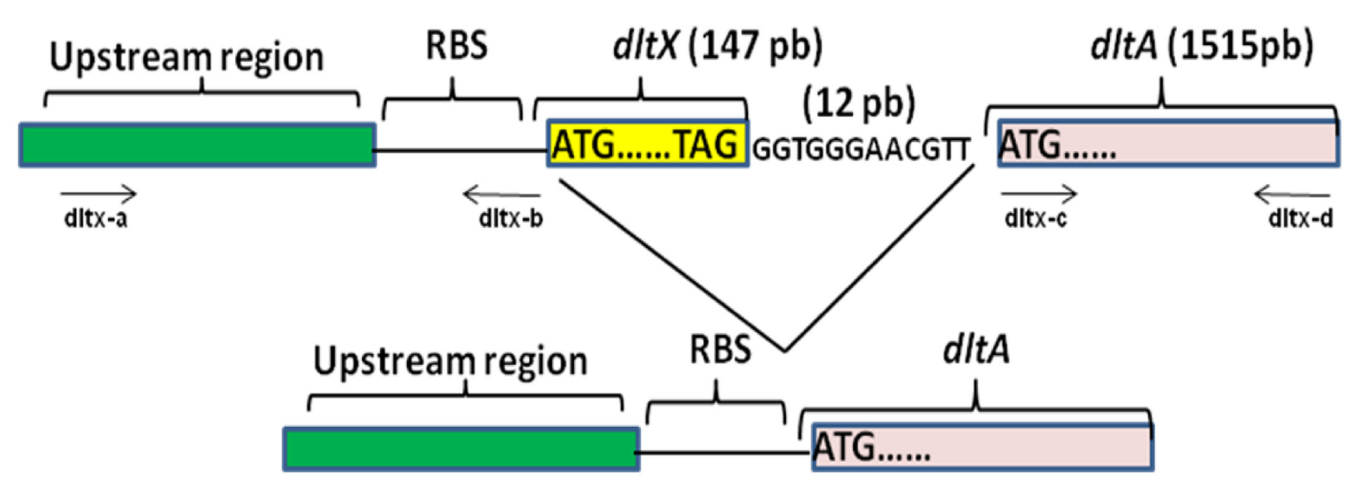

insertion into the chromosome
via homologous recombination

FIGURE 2 | Schematic diagram showing the construction of an in frame deletion of the dltX gene by Splicing by Overlap Extension (SOE). The top part of the diagram shows the DNA fragment containing the upstream and downstream DNA regions flanking dlt $X$. Synthetic oligonucleotides are represented by lines with arrows indicating the $5^{\prime}-3^{\prime}$ orientation. Oligo dltX-b $3^{\prime}$ and oligo dltX-c $5^{\prime}$ match their respective template DNA sequences in their $3^{\prime}$ portions and are complementary to each other in their $5^{\prime}$ portions. The double stranded DNA products generated in separate PCR reactions were denatured, allowed to anneal at their overlap and were $3^{\prime}$ extended by DNA polymerase. The fusion product was then further amplified by PCR in the presence of oligo dltX-a and oligo dltX-d.

method, which introduces a deletion without the use of antibiotic resistance cassettes (Figure 2). As a result of this deletion, the other genes of the operon are placed directly under the control of the upstream promoter region and are not affected in transcription. We first investigated WT and $\Delta d l t X$ mutant growth dynamics by following optical density (at $600 \mathrm{~nm}$ ) in liquid cultures and did not detect any significant differences in bacterial growth and cell doubling time. We then used a reporter construct in which the $d l$ upstream promoter region was fused to $g f p$, to investigate whether the deletion of $d l t X$ affects the transcriptional regulation of the $d l t$ operon. We introduced the construct into WT and $\Delta d l t X$ mutant backgrounds and quantified $g f p$ expression in both strains. We found no differences in the expression of Pdlt $\Omega g f p$ fusions (data not shown) between strains. We also performed RT-qPCR to examine the abundance of $d l t A \mathrm{mRNA}$, in WT and $\Delta d l t X$ strains, during the mid-exponential growth phase in standard LB medium. We observed no differences in dltA expression between WT and dltX mutant cells. Together, these findings indicate that DltX does not affect the transcription of the operon.

\section{Morphological Characteristics of WT and the dItX Deletion Mutant}

We used SEM to analyze cells collected in mid-log phase to examine phenotypical differences between WT and dltX mutant strains. Deletion of $d l t X$ strongly affected cell surface morphology (Figure 3). WT cells had a typical rod shape with a regular and smooth surface (Figure 3A), whereas the dltX mutant cells had an irregular and wrinkled shape, and showed rib-like protrusions on their surface (Figure 3B). Complemented mutant cells (Figure 3C) showed an appearance similar to that of WT cells.

\section{The dltX Mutant Is Sensitive to Polymyxin B and Nisin In Vitro}

We compared the growth of WT Bt 407, Bt 407 $\Delta d l t X$ mutant and complemented mutant strain Bt 407 $\Delta d l t X$ (pHT304-18 $\Omega d l t$ ) exposed to polymyxin B or Nisin, to determine if dltX has a direct role in resistance to CAMPs. Addition of $150 \mu \mathrm{g}$ polymyxin $\mathrm{B} \mathrm{m} \mathrm{m}^{-1}$ or $75 \mu \mathrm{g} \mathrm{Nisin} \mathrm{ml}^{-1}$ to a growing culture caused immediate growth interruption of the mutant whereas WT and complemented strains were not affected (data not shown). Therefore, the dltX mutant is highly susceptible to CAMPs and its complementation with $d l t X$ completely restored the resistant parental phenotype. Moreover, the IC50 value of polymyxin B was 35 fold lower in the $\Delta d l t X$ mutant than in either the WT or complemented strains. Precisely, the $\mathrm{IC}_{50}$ value of the $\Delta d$ dt X mutant was $13.9 \mu \mathrm{g} \mathrm{ml}^{-1}$, that of the WT was $484 \mu \mathrm{g} \mathrm{ml}^{-1}$, and that of the complemented strain was $503 \mu \mathrm{g} \mathrm{ml}^{-1}$ (Figure 4). These results indicate that $d l t X$ is necessary for $B$. thuringiensis resistance to polymyxin $\mathrm{B}$ and that transcription of dltABCD alone under the control of the upstream promoter region is not sufficient to confer resistance.

\section{Deletion of dItX Leads to Attenuated Virulence in Galleria mellonella}

The finding that $d l t X$ is essential for the resistance of $\mathrm{Bt} 407$ to CAMPs led us to investigate the effect of its deletion on bacterial virulence in two insect models. We injected $10^{4}$ vegetative cells of the WT, mutant, or complemented strains into fifth instar G. mellonella larvae and compared their virulence by monitoring the mortality level of Galleria infected with the different strains (Figure 5). The WT and complemented strains were significantly more virulent in insects $(p<0.0001)$ than the dltX mutant strain (Figure 5). In fact, virulence in G. mellonella was almost completely abolished in the $d l t X$ mutant (13\% mortality) whereas 
A

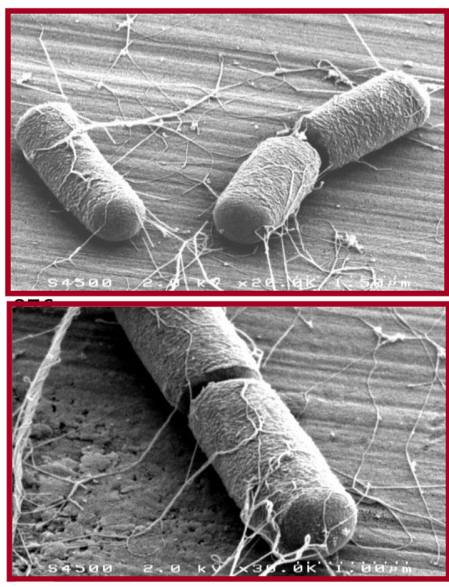

B

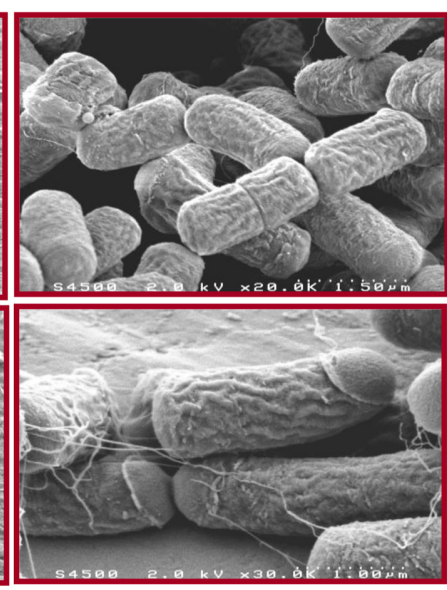

C

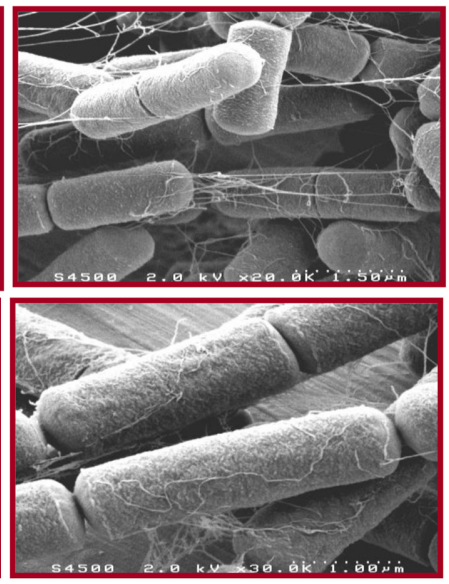

FIGURE 3 | Effects of $d l t X$ deletion on Bt 407 cells. Scanning electron micrographs show exponential growth phase cells of WT (A), $\Delta d l t X$ (B), and $\Delta d l t X$ complemented cells (C) in $Y$ buffer ( $\mathrm{pH}$ 5.6). Magnifications are $\times 20 \mathrm{~K}$ and $\times 30 \mathrm{~K}$. The dotted lines on pictures in the top panel represent a scale of 1.5 $\mu \mathrm{m}$ ( $\mathrm{x} 20 \mathrm{~K}$ magnification) and those in the bottom panel represent a scale of $1 \mu \mathrm{m}$ ( $x 30 \mathrm{~K}$ magnification).

WT and complemented strains were highly virulent and gave almost $100 \%$ mortality $48 \mathrm{~h}$ post-infection.

\section{The Low Virulence of the ditX Mutant Is Directly Correlated with Its Sensitivity to the Humoral CAMP Response In Vivo}

The immune system in insects comprises cellular and humoral responses that have been largely investigated in the model organism Drosophila melanogaster (Lemaitre and Hoffmann, 2007). The humoral response involves the infection-induced activation of NF- $\kappa \mathrm{B}$ transcription factors, Dif and Relish, which in turn activate AMP encoding genes. Dif is downstream from the Toll pathway and Relish is downstream from the IMD pathway (Hedengren et al., 1999; Rutschmann et al., 2000). These signaling cascades are specifically elicited by microbial associated molecular patterns (MAMPs) that are detected by cognate pattern recognition receptors (PRRs), which are members of the Peptidoglycan Recognition Receptor and Glucan Binding Receptor families (Ferrandon et al., 2007). Notably, the Toll pathway is triggered upon sensing of Lysine (Lys)-type peptidoglycan, which is a common component of most Gram-positive bacteria, whereas the IMD pathway is activated by the mesodiaminopilmelic acid (DAP)-type peptidoglycan common to Gram-negative bacteria (Leulier et al., 2003; Ferrandon et al., 2007). The wall of all B. cereus group species also consists of a DAP-type peptidoglycan (Vollmer et al., 2008). We therefore, compared the virulence of WT, $\Delta$ dltX, and the complemented strain in WT oregon $\mathrm{R}$ and relish mutant flies to confirm that the loss of virulence phenotype of the $\Delta d l t X$ mutant is associated with its susceptibility to CAMPs in vivo. Bt407 was resistant to the fly humoral response because WT and relish immunodeficient insects exhibited similar survival curves with high lethality of the infected flies at $15 \mathrm{~h}$ post-infection (Figure 6). Similar to findings obtained with Galleria larvae, survival curves of WT flies infected with the $\Delta d l t X$ mutant showed that loss of $d l t X$ is sufficient to significantly impair virulence. Indeed, $75 \%$ of the flies infected with the $\Delta d l t X$ mutant survived $24 \mathrm{~h}$ post-infection. Interestingly however, the virulence of the $\Delta d l t X$ mutant was fully restored in relish mutant flies which do not produce CAMPs in response to the infection. This phenotype is associated with the loss of DltX because the complemented strain was as virulent as the WT strain in both WT oregon $R$ and relish mutant flies. These findings clearly demonstrate that DltX is required for the resistance of Bt 407 to the humoral antimicrobial response of Drosophila infected by injection into the hemocoel.

\section{DItX Is Involved in the D-Alanylation of TAs}

We sought to determine whether the sensitivity of the dltX mutant to CAMPs was due to impairment in the incorporation of D-alanyl esters into TAs of the cell wall. D-Alanine was released by mild alkaline hydrolysis from whole heat-inactivated bacterial cells and quantified by HPLC analysis. Almost no $\mathrm{D}$-alanine was released from the cell walls of the $\Delta d l t X$ mutant, contrary to what is observed for the WT Bt 407, indicating that D-alanylation of TA was significantly impaired in the mutant. D-alanine amount released from the complemented strain was significantly higher than the one released from WT strain. This result can be explained by the copy number of the plasmid used for complementation (Figure 7).

\section{Deletion of dItX Significantly Alters Ionic Surface Charge}

The loss of $\mathrm{D}$-alanylation in the dltX mutant may result in a net change in electrical charge of the bacterial surface, which may explain the higher sensitivity of the $d l t X$ mutant to CAMPs both in vitro and in vivo. We measured the electrophoretic mobility (EM) of each strain to see if the deletion of $d l t X$ was associated 

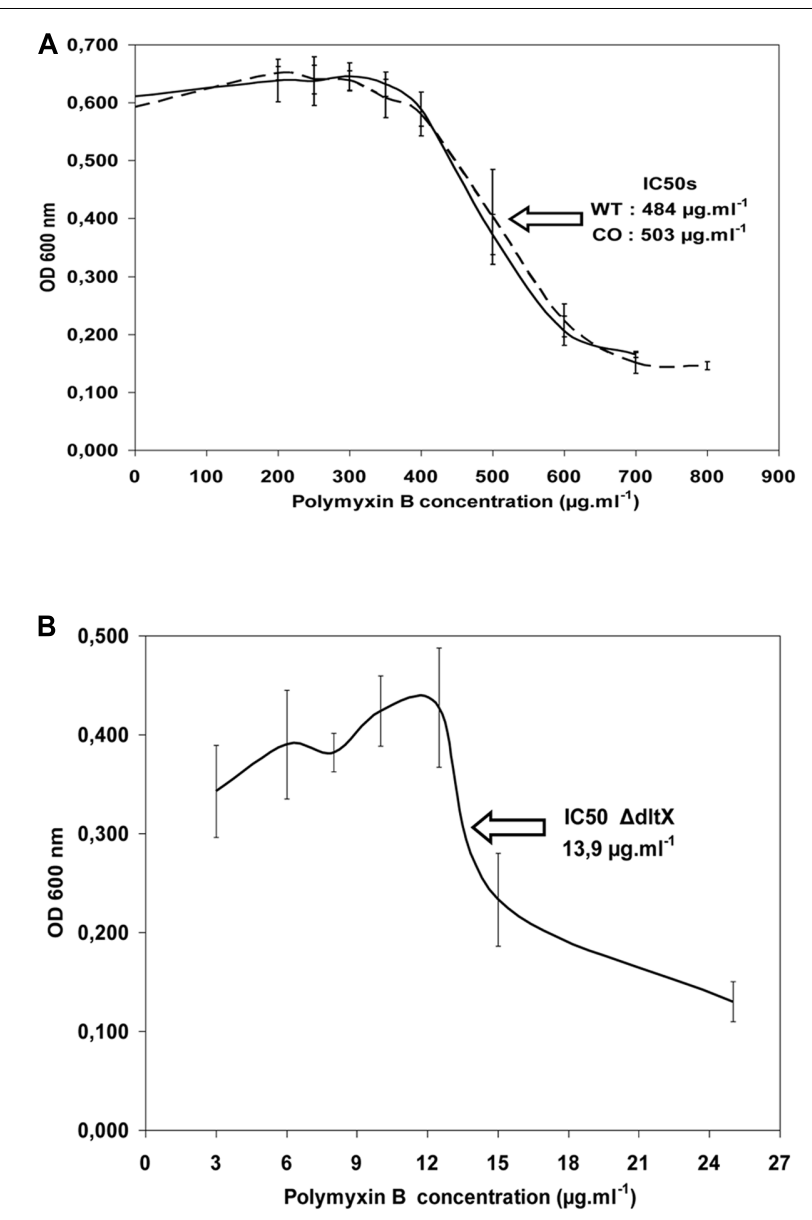

FIGURE 4 | Half inhibitory concentration $\left(\mathrm{IC}_{50}\right)$ of WT 407 (solid line) and $\Delta$ dltX complemented strains (CO) (broken line) (A), and the $\Delta$ dltX mutant (B). Bacterial growth was scored after $6 \mathrm{~h}$ of inoculation. The results shown are the means of at least three independent experiments performed in duplicate.

with a change of the global charge at the bacterial surface. EM was significantly higher in the $\Delta d l t X$ mutant than in the WT strain ( $p=0.0007$ ) (Figure 8), showing that deletion of $d l t X$ alters electrical surface charge. Thus, the $\Delta d l t X$ strain has a high negative charge at its surface.

\section{DISCUSSION}

The dlt operon encodes proteins that are responsible for the incorporation of D-alanine into TAs, which is an important process for bacterial resistance to CAMP's. However, the functions of several $d l t$ genes remain unclear and are still under investigation. Moreover, few studies have indicated that $d l t X$ may be part of the dlt operon despite the fact that the gene is present in the genomes of 807 bacteria belonging to the Firmicutes phylum, as revealed by our in silico analysis. This is probably due to the fact, that, in the original genomes annotations, the small ORF preceding the dltABCD genes has been frequently missed due to its small size. Therefore, the involvement of the gene product of
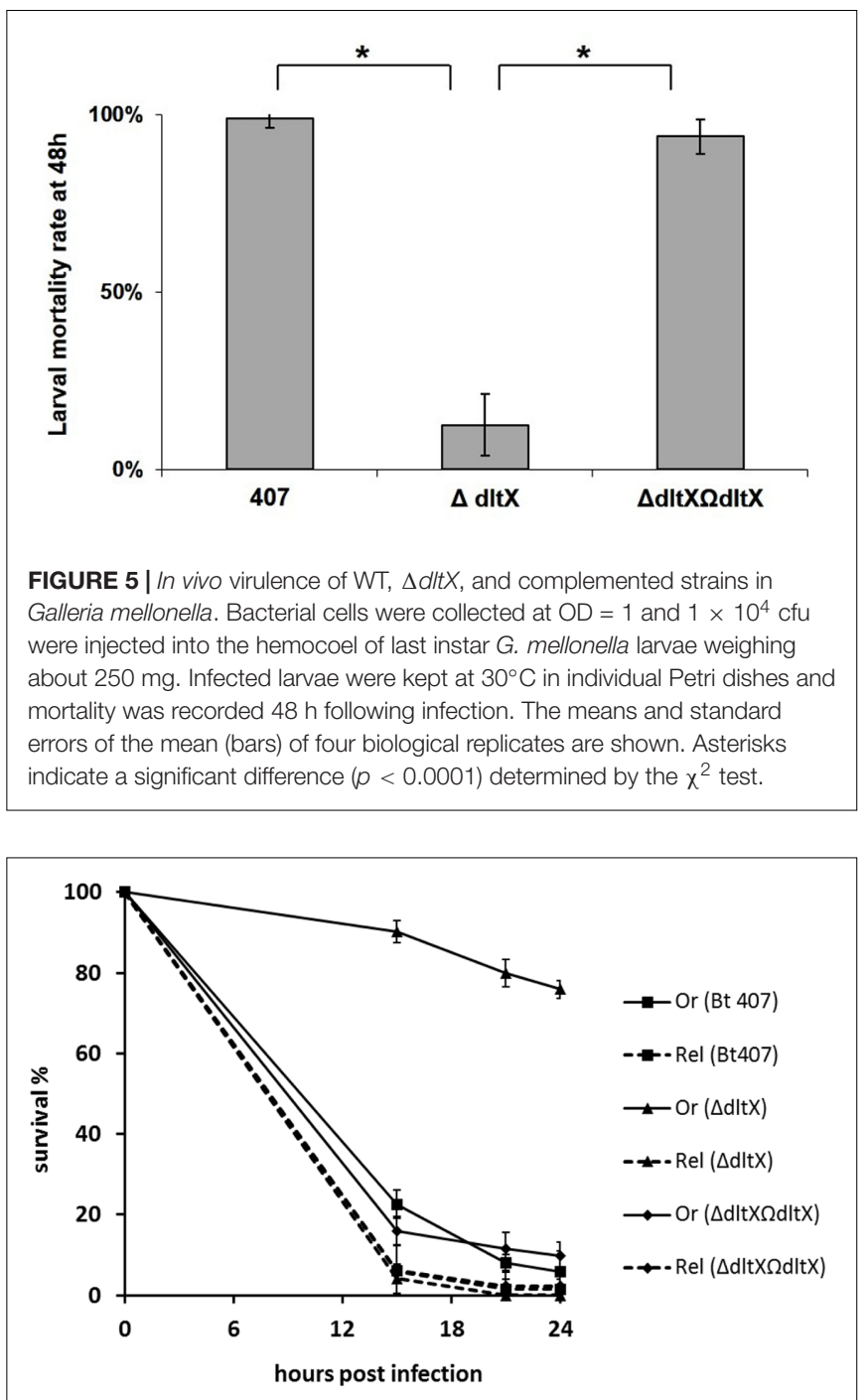

FIGURE 6 | Survival analysis of Drosophila melanogaster adult flies infected with WT, $\Delta d l t X$, and complemented bacterial strains. Relish (Rel) flies were used as immunocompromised mutants of the Imd pathway and wild type (WT) Oregon (Or) flies were used as an immunocompetent control in these experiments. These flies were infected with WT, $\Delta d$ lt $X$, or complemented strains and survival was recorded at various time points post-infection. The means and standard errors of the mean (bars) of three independent experiments are shown.

dltX in the function of this operon has never been investigated until now despite the fact that its sequence is highly conserved among Gram positive Firmicute family bacteria, which suggests that the product of this gene could be important and involved in the D-alanylation process.

In the present study, we used the human opportunistic and entomopathogenic bacterium $B$. thuringiensis crystal minus strain 407 and investigated the role of $d l t X$ in the resistance of this pathogen to cationic antimicrobial host components. In strain $B t$ 407 dlt $X$ is transcribed along with the other genes of the operon such as already found in several other species such as $S$. aureus or Lactobacillus plantarum (Koprivnjak et al., 2006; Palumbo et al., 


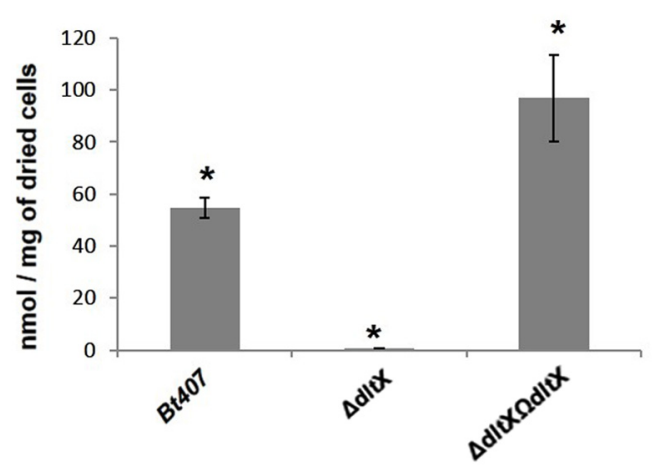

FIGURE 7 | Amounts of D-alanine released from whole cells by alkaline hydrolysis for WT, mutant, and complemented strains. The mean values and standard deviations (black bars) of results from three independent experiments are shown. Asterisks indicate a significant difference $(p<0.0001)$ determined by the $\chi^{2}$ test.

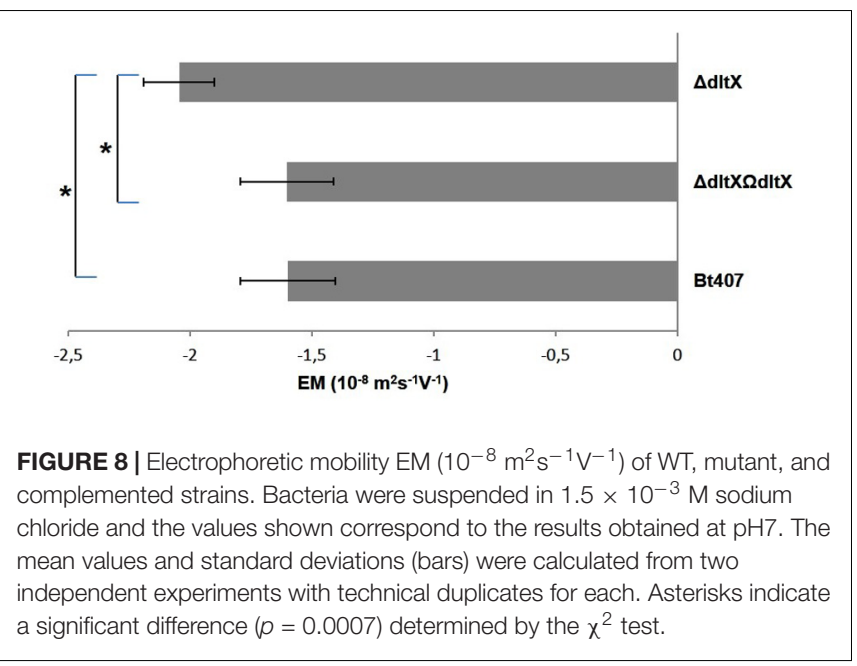

2006; Bron et al., 2012). We first constructed a $d l t X$ mutant by allelic exchange, in which the dlt $A B C D$ genes were intact and expressed under the control of their endogenous promoter. The resulting $d l t X$ mutant had a pleiotropic phenotype, including changes in bacterial cell morphology, high susceptibility to bacterial and insect cationic AMPs, and attenuated virulence in two insect infection models. These observations demonstrate that functional DltX is essential for resistance to CAMPs. Moreover, we found that no D-alanine was released from the cell walls of the $\Delta d l t X$ mutant, unlike the WT or complemented strains, suggesting that the loss of $d l t X$ function results in the complete absence of $\mathrm{D}$-alanylation. This was an unexpected finding because previous reports have claimed that the DltA-D proteins are necessary and sufficient for D-Alanine incorporation and these proteins were not inactivated in our mutant (Perego et al., 1995; Neuhaus et al., 1996; Neuhaus and Baddiley, 2003). Indeed, we have demonstrated, both by RT-qPCR and by activity of a $g f p$ reporter construct, that transcription of the other genes of the $d l t$ operon is not affected by the absence of $d l t X$. Moreover, complementation of the mutant strain with dltX resulted in the complete restoration of all analyzed phenotypes. These findings suggest that DltX does not act as a cis or trans element that regulates transcription of the operon, but plays a direct biosynthetic, transport or addresser role in D-alanylation. We have also performed a complementation of the $\Delta d l t X$ mutant with a mutated form of $d l t X$ in which the start codon (ATG) was replaced by a stop codon (TGA) thus impeding the translation of the putative DltX protein (data not shown). Unlike the native $d l t X$ sequence, this mutated form of $d l t X$ could not restore the parental phenotype of resistance to CAMPs and virulence toward G. mellonella. However, the exact function of DltX remains to be elucidated.

We also observed that disruption of $d l t X$ strongly affected the cell morphology of $B$. thuringiensis since the $\Delta d l t X$ mutant strain presented irregular shapes which were not observed in the parental strain (Figure 3). Such dramatic changes in cell morphology have not been reported for other $\Delta d l$ mutants of gram positive bacteria, except for L. plantarum. Indeed, scanning and transmission electron microscopy (SEM and TEM) of a $L$. plantarum $\Delta d l t$ mutant showed perforations of the cell envelope (Palumbo et al., 2006). The authors suggested that this effect may result from a high rate of autolysis. We observed no differences between the growth curve of the WT parental strain and that of the $\Delta d l t X$ mutant (data not shown). This indicates that the surface modifications are unlikely to influence the rate of autolysis, at least in vitro and under the conditions tested. Moreover, we showed that the cell surface of the $\Delta d l t X$ mutant was significantly more negatively charged than that of the WT strain. This is not surprising because the cell wall is predicted to be largely more anionic in the absence of positively charged D-alanyl esters. However, in contrast with our results, Giaouris et al. (2008) found that the level of D-alanylation in the cell wall of Lactococcus lactis did not significantly modify the global surface charge. They suggested that most D-alanyl substituents of TAs are located inside the cell wall and are not exposed at the cell surface, which may explain why electrophoretic mobility was not affected in this mutant strain. Thus, the inactivation of the dlt operon has a wide range of physiological consequences in different bacteria, but the absence of D-alanyl esters in the TAs does not result in a clear morphological phenotype that is common to all the bacterial species harboring a dlt operon except their higher sensitivity to CAMPs (Peschel et al., 2000; Fabretti et al., 2006).

DltA, dltB, dltC, or dltD mutants of several bacteria show high susceptibility to CAMPs and are killed by peptides of host defense mechanisms (Poyart et al., 2003; Kovács et al., 2006; Abi Khattar et al., 2009; McBride and Sonenshein, 2011). We now show that DltX is also involved in the response to antimicrobial peptides. Indeed, inactivation of dltX alone (without affecting the expression of $d l t A B C D$ ) also substantially impaired the resistance of $B$. thuringiensis to CAMPs (Figure 4) and significantly attenuated $B$. thuringiensis virulence in insect larvae (Figures 5, 6).

We also took advantage of the Drosophila melanogaster infection model to demonstrate the prominent role of the Dalanylation of TAs during bacterial resistance to the antimicrobial response in vivo. Indeed, both Oregon $R \mathrm{WT}$, and relish mutant flies (that do not produce AMPs in response to 


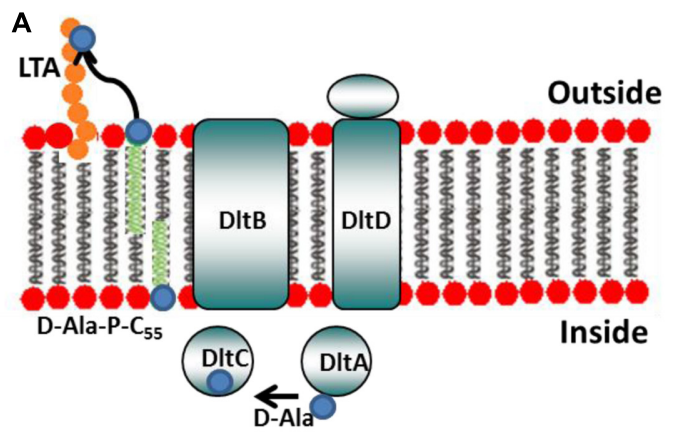

Fischer model

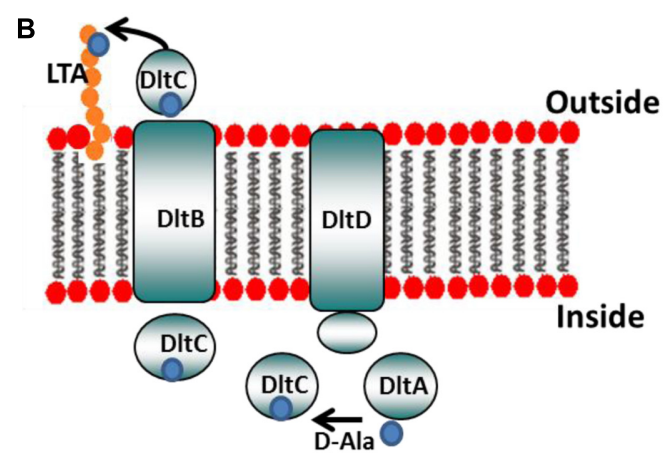

Nehaus and Baddiley model

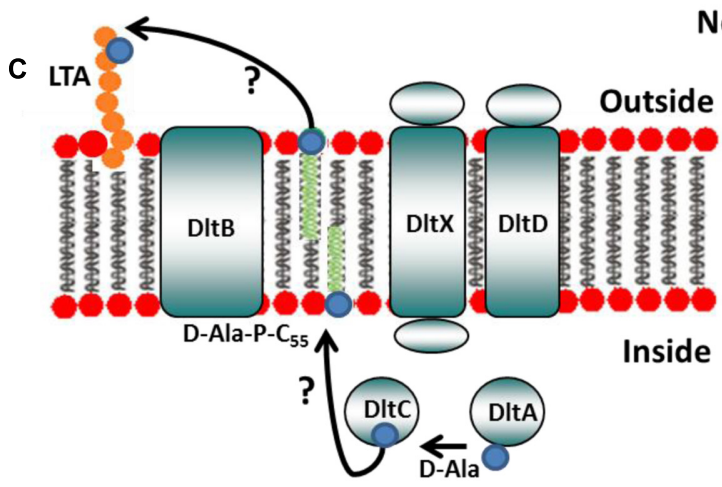

Revised model including DltX

FIGURE 9 | Models of D-alanine substitution of LTA. (A) Fischer model: DltA ligates D-alanine (small blue circle) onto the carrier protein DltC. DItB then transfers $\mathrm{D}$-alanine from DItC to undecaprenyl-phosphate $\left(\mathrm{C}_{55}-\mathrm{P}\right)$ to produce D-Ala-P-C 55 . This lipid linked intermediate is, then, flipped accross the membrane, whereas DltD, active at the outer side of the membrane, transfers D-Ala to LTA (adapted from reference 5). (B) Neuhaus and Baddiley model. DltA ligates D-alanine (small blue circle) onto the carrier protein DltC. DItD is thought to facilitate D-alanine ligation to DltC and DltB is believed to be involved in the translocation of Alanylated-DltC across the membrane where it may then transfer D-alanine directly onto LTA (adapted from reference 5). (C) Revised model including DltX: our results show that DltX is essential for D-alanylation of TAs. Therefore, DltX was included onto the existing models to obtain a more complete picture of the mechanism of D-alanine incorporation into the cell wall polymers of Gram-positive bacteria. DltX, due to its alpha-helical structure prediction and the presence of both extracellular and cytosolic domains, can theoretically interact with the four other proteins of the operon (see hypotheses in the text). However, the exact functions of DitX as well as DltB and DltD in this process remain to be elucidated.

infection), were highly susceptible to infection by WT $B t$ 407. By contrast, virulence of Bt $407 \Delta d l t X$ was significantly attenuated, as revealed by the survival of a large proportion of oregon $R$ WT adult flies infected with the $\Delta d l t X$ mutant, but retained its pathogenic effect on relish mutants (Figure 6). Hence, the process of D-alanylation may be essential for the persistence, development, and multiplication of the bacteria in an antimicrobial hostile environment. These findings also indicate that in the absence of antimicrobial peptides, the $\Delta d l t X$ mutant possesses efficient resistance strategies to deal with the other mechanisms of host defense, such as cellular or melanization responses (Nielsen-LeRoux et al., 2012). It will be interesting to investigate these strategies in the B. cereus-Drosophila interaction model.

Moreover, based on our results, we propose that the two existing models that describe the functions of the proteins encoded by dltABCD should be amended to include dltX, to obtain a complete picture of the mechanism of D-alanine incorporation into the cell wall polymers of Gram-positive bacteria (Figure 9). This model takes into account the recent findings of Reichmann et al. (2013) that showed that DltC does not cross the membrane and that DltD is anchored to the outside of the cell. Therefore, it is unlikely that the carrier protein DltC is involved in the final step of D-alanylation on the outside of the cell, and that DltD, which is active at the outer side of the membrane, facilitates $\mathrm{D}$-alanine ligation to DltC, as proposed by Neuhaus and Baddiley. DltB is predicted to be an integral membrane protein with 12 transmembrane spanning alpha helixes. In this model, DltX, due to its alphahelical structure prediction and the presence of both extracellular and intracytoplasmic domains, can theoretically interact with any of the four other proteins of the operon (DltA, DltB, DltC, or DltD), or even with several of them. We can consider first, that it is the intracytoplasmic domain of DltX which is involved, and which interact with one of the intracellular components (DltA or DltC). Could DltX play the role of the intermediate undecaprenol-phosphate (which has not yet been confirmed experimentally) or could it help in the transfer of D-alanine from DltC to this lipid linked intermediate? Another possibility is that DltX plays the role of a flippase which flips the D-alanylated 
undecaprenol-phosphate across the membrane. An alternative, is that the transmembrane segment of DltX interacts with one of the transmembrane domains of DltB and contributes to the transfer of molecules (such as D-alanine) through the membrane channel formed by DltB. A fourth possibility is that it is the extracellular domain which is involved in the activity of DltX. This domain could interact with the D-alanylated undecaprenol-phosphate, once it is exposed on the outside of the membrane, and be necessary, together with DltD, for the transfer and/or ligation of $\mathrm{D}$-alanine to TAs. It is interesting to note that only two amino acids are completely conserved in all DltX proteins described to date, one is located in the transmembrane alpha helix and the other in the extracytoplasmic domain. It is important now to confirm the interaction of DltX with one of these proteins. Moreover, our results show that the wall structure is strongly affected in the dltX mutant; this might indicate that DltX could interacts with other proteins or enzymes independent of the $d l t$ operon, involved in the synthesis of some elements of the cell wall.

\section{CONCLUSION}

Our data clearly demonstrate that the synthesis of D-alanylTAs cannot be accomplished only by the concerted action of the four proteins encoded by the $\operatorname{dlt} A, d l t B, d l t C$, and $d l t D$ genes, as it frequently suggested in many studies. We have shown that the gene product of $d l t X$ is also essential in this process. Future studies addressing the mechanism of D-alanine incorporation into TAs should take into account that DltX is also necessary and essential for the the D-alanylation of TAs.

\section{REFERENCES}

Abachin, E., Poyart, C., Pellegrini, E., Milohanic, E., Fiedler, F., Berche, P., et al. (2002). Formation of D-alanyl-lipoteichoic acid is required for adhesion and virulence of Listeria monocytogenes. Mol. Microbiol. 43, 1-14. doi: 10.1046/j. 1365-2958.2002.02723.x

Abi Khattar, Z., Rejasse, A., Destoumieux-Garzón, D., Escoubas, J. M., Sanchis, V., Lereclus, D., et al. (2009). The dlt operon of Bacillus cereus is required for resistance to cationic antimicrobial peptides and for virulence in insects. J. Bacteriol. 191, 7063-7073. doi: 10.1128/JB.00892-09

Bouillaut, L., Ramarao, N., Buisson, C., Gilois, N., Gohar, M., Nielsen-Leroux, C., et al. (2005). FlhA influences Bacillus thuringiensis PlcR-regulated gene transcription, protein production, and virulence. Appl. Environ. Microbiol. 71, 8903-8910. doi: 10.1128/AEM.71.12.8903-8910.2005

Bravo, A., Agaisse, H., Salamitou, S., and Lereclus, D. (1996). Analysis of cryIAa expression in sigE and sigK mutants of Bacillus thuringiensis. Mol. Gen. Genet. 250, 734-741. doi: 10.1007/BF02172985

Bron, P. A., Tomita, S., van Swam, I. I., Remus, D. M., Meijerink, M., Wels, M., et al. (2012). Lactobacillus plantarum possesses the capability for wall teichoic acid backbone alditol switching. Microb. Cell Fact. 11:123. doi: 10.1186/14752859-11-123

Brown, S., Santa Maria, J. P. Jr., and Walker, S. (2013). Wall teichoic acids of grampositive bacteria. Annu. Rev. Microbiol. 67, 313-336. doi: 10.1146/annurevmicro-092412-155620

Chan, K. G., Mayer, M., Davis, E. M., Halperin, S. A., Lin, T.-J., and Lee, S. F. (2007). Role of D-alanylation of Streptococcus gordonii lipoteichoic acid in
However, additional work is now needed to elucidate the function of DltX and with which other(s) protein(s) of the operon it interacts.

\section{AUTHOR CONTRIBUTIONS}

RK: designed experiments, performed the experiments, analyzed and wrote the manuscript, AR: performed the experiments, IJ: performed the experiments, ZA: performed the experiments, PC and M-PC-C: conceived experiments and analyzed data, CN-L and DL: conceived experiments and analyzed data, LC: designed experiments and analyzed the data, MK and VS-B: conceived and designed the study, analyzed the data and wrote the manuscript.

\section{FUNDING}

RK held a "Mobilité Scientifique et Universitaire fellowship" from the Agence Universitaire de la Francophonie (AUF), Lebanon. ZA was funded by the National Council for Scientific Research in Lebanon. This project has been funded with support from the research council of the Saint-Joseph University (Project FS59), the National Council for Scientific Research in Lebanon (245004) and the CEDRE program (32942VD).

\section{ACKNOWLEDGMENT}

We thank Romain Briandet, Jean-Marie Herry, and Alexis Canette from the MIMA2 platform for technical assistance and for access to microscopic and electrophoretic mobility facilities (www.jouy.inra.fr/mima2).

innate and adaptive immunity. Infect. Immun. 75, 3033-3042. doi: 10.1128/IAI. 01549-06

Collins, L. V., Kristian, S. A., Weidenmaier, C., Faigle, M., van Kessel, K. P., Van Strijp, J. A., et al. (2002). Staphylococcus aureus strains lacking D-alanine modifications of teichoic acids are highly susceptible to human neutrophil killing and are virulence attenuated in mice. J. Infect. Dis. 186, 214-219. doi: $10.1086 / 341454$

Daou, N., Buisson, C., Gohar, M., Vidic, J., Bierne, H., Kallassy, M., et al. (2009). IlsA, a unique surface protein of Bacillus cereus required for iron acquisition from heme, hemoglobin and ferritin. PLoS Pathog. 5:e1000675. doi: 10.1371/ journal.ppat.1000675

Debabov, D. V., Heaton, M. P., Zhang, Q., Stewart, K. D., Lambalot, R. H., and Neuhaus, F. C. (1996). The D-Alanyl carrier protein in Lactobacillus casei: cloning, sequencing, and expression of dltC. J. Bacteriol. 178, 3869-3876. doi: 10.1128/jb.178.13.3869-3876.1996

Debabov, D. V., Kiriukhin, M. Y., and Neuhaus, F. C. (2000). Biosynthesis of lipoteichoic acid in Lactobacillus rhamnosus: role of Dlt $\mathrm{D}$ indalanylation. J. Bacteriol. 182, 2855-2864. doi: 10.1128/JB.182.10.2855-286 4.2000

D’Elia, M. A., Millar, K. E., Beveridge, T. J., and Brown, E. D. (2006a). Wall teichoic acid polymers are dispensable for cell viability in Bacillus subtilis. J. Bacteriol. 188, 8313-8316. doi: 10.1128/JB.01336-06

D’Elia, M. A., Pereira, M. P., Chung, Y. S., Zhao, W., Chau, A., Kenney, T. J., et al. (2006b). Lesions in teichoic acid biosynthesis in Staphylococcus aureus lead to a lethal gain of function in the otherwise dispensable pathway. J. Bacteriol. 188, 4183-4189. doi: 10.1128/JB.00197-06 
Dower, W. J., Miller, J. F., and Ragsdale, C. W. (1988). High efficiency transformation of E. coli by high voltage electroporation. Nucleic Acids Res. 16, 6127-6145. doi: 10.1093/nar/16.13.6127

Fabretti, F., Theilacker, C., Baldassarri, L., Kaczynski, Z., Kropec, A., Holst, O., et al. (2006). Alanine esters of enterococcal lipoteichoic acid play a role in biofilm formation and resistance to antimicrobial peptides. Infect. Immun. 74, 4164-4171. doi: 10.1128/IAI.00111-06

Ferrandon, D., Imler, J.-L., Hetru, C., and Hoffmann, J. A. (2007). The Drosophila systemic immune response: sensing and signalling during bacterial and fungal infections. Nat. Rev. Immunol. 7, 862-874. doi: 10.1038/ nri2194

Fischer, W. (1988). Physiology of lipoteichoic acids in bacteria. Adv. Microb. Physiol. 29, 233-302. doi: 10.1016/S0065-2911(08)60349-5

Fischer, W. (1994). Lipoteichoic acid and lipids in the membrane of Staphylococcus aureus. Med. Microbiol. Immunol. 183, 61-76. doi: 10.1007/BF00277157

Fischer, W., Mannsfeld, T., and Hagen, G. (1990). On the basic structure of poly (glycerophosphate) lipoteichoic acids. Biochem. Cell. Biol. 68, 33-43. doi: 10.1139/090-005

Fischer, W., and Rösel, P. (1980). The alanine ester substitution of lipoteichoic acid (LTA) in Staphylococcus aureus. FEBS Lett. 119, 224-226. doi: 10.1016/00145793(80)80257-2

Fisher, N., Shetron-Rama, L., Herring-Palmer, A., Heffernan, B., Bergman, N., and Hanna, P. (2006). The dltABCD operon of Bacillus anthracis Sterne is required for virulence and resistance to peptide, enzymatic, and cellular mediators of innate immunity. J. Bacteriol. 188, 1301-1309. doi: 10.1128/JB.188.4.1301-1309. 2006

Giaouris, E., Briandet, R., Meyrand, M., Courtin, P., and Chapot-Chartier, M.-P. (2008). Variations in the degree of D-alanylation of teichoic acids in Lactococcus lactis alter resistance to cationic antimicrobials but have no effect on bacterial surface hydrophobicity and charge. Appl. Environ. Microbiol. 74, 4764-4767. doi: 10.1128/AEM.00078-08

Heaton, M. P., and Neuhaus, F. C. (1992). Biosynthesis of D-alanyl-lipoteichoic acid: cloning, nucleotide sequence, and expression of the Lactobacillus casei gene for the D-alanine-activating enzyme. J. Bacteriol. 174, 4707-4717. doi: $10.1128 / \mathrm{jb}$.174.14.4707-4717.1992

Heaton, M. P., and Neuhaus, F. C. (1994). Role of the D-alanyl carrier protein in the biosynthesis of D-alanyl-lipoteichoic acid. J. Bacteriol. 176, 681-690. doi: 10.1128/jb.176.3.681-690.1994

Hedengren, M., Dushay, M. S., Ando, I., Ekengren, S., Wihlborg, M., Asling, B., et al. (1999). Relish, a central factor in the control of humoral but not cellular immunity in Drosophila. Mol. Cell 4, 827-837. doi: 10.1016/S1097-2765(00) 80392-5

Kochhar, S., and Christen, P. (1989). Amino acid analysis by high-performance liquid chromatography after derivatization with 1-fluoro-2, 4-dinitrophenyl5-L-alanine amide. Anal. Biochem. 178, 17-21. doi: 10.1016/0003-2697(89) 90348-5

Koprivnjak, T., Mlakar, V., Swanson, L., Fournier, B., Peschel, A., and Weiss, J. P. (2006). Cation-induced transcriptional regulation of the dlt operon of Staphylococcus aureus. J. Bacteriol. 188, 3622-3630. doi: 10.1128/JB.188.10. 3622-3630.2006

Kovács, M., Halfmann, A., Fedtke, I., Heintz, M., Peschel, A., Vollmer, W., et al. (2006). A functional dlt operon, encoding proteins required for incorporation of d-alanine in teichoic acids in gram-positive bacteria, confers resistance to cationic antimicrobial peptides in Streptococcus pneumoniae. J. Bacteriol. 188, 5797-5805. doi: 10.1128/JB.00336-06

Kristian, S. A., Datta, V., Weidenmaier, C., Kansal, R., Fedtke, I., Peschel, A., et al. (2005). D-alanylation of teichoic acids promotes group a streptococcus antimicrobial peptide resistance, neutrophil survival, and epithelial cell invasion. J. Bacteriol. 187, 6719-6725. doi: 10.1128/JB.187.19.6719-6725.2005

Lecadet, M., Blondel, O., and Ribier, J. (1980). A semi-defined medium for growth and sporulation in Bacillus thuringiensis Berliner and many other strains. J. Gen. Microbiol. 121, 203-212.

Lemaitre, B., and Hoffmann, J. (2007). The host defense of Drosophila melanogaster. Annu. Rev. Immunol. 25, 697-743. doi: 10.1146/annurev. immunol.25.022106.141615

Lereclus, D., Arantes, O., Chaufaux, J., and Lecadet, M.-M. (1989). Transformation and expression of a cloned $\delta$-endotoxin gene in Bacillus thuringiensis.
FEMS Microbiol. Lett. 60, 211-217. doi: 10.1111/j.1574-6968.1989. tb03448.x

Leulier, F., Parquet, C., Pili-Floury, S., Ryu, J.-H., Caroff, M., Lee, W. J., et al. (2003). The Drosophila immune system detects bacteria through specific peptidoglycan recognition. Nat. Immunol. 4, 478-484. doi: 10.1038/ni922

Ligoxygakis, P., Pelte, N., Hoffmann, J. A., and Reichhart, J.-M. (2002). Activation of Drosophila Toll during fungal infection by a blood serine protease. Science 297, 114-116. doi: 10.1126/science.1072391

McBride, S. M., and Sonenshein, A. L. (2011). The dlt operon confers resistance to cationic antimicrobial peptides in Clostridium difficile. Microbiology 157, 1457-1465. doi: 10.1099/mic.0.045997-0

Neuhaus, F. C., and Baddiley, J. (2003). A continuum of anionic charge: structures and functions of D-alanyl-teichoic acids in gram-positive bacteria. Microbiol. Mol. Biol. Rev. 67, 686-723. doi: 10.1128/MMBR.67.4.686-723.2003

Neuhaus, F. C., Heaton, M. P., Debabov, D. V., and Zhang, Q. (1996). The dlt operon in the biosynthesis of D-alanyl-lipoteichoic acid in Lactobacillus casei. Microb. Drug Resist. 2, 77-84. doi: 10.1089/mdr.1996.2.77

Nguyen, L. T., Haney, E. F., and Vogel, H. J. (2011). The expanding scope of antimicrobial peptide structures and their modes of action. Trends Biotechnol. 29, 464-472. doi: 10.1016/j.tibtech.2011.05.001

Nielsen-LeRoux, C., Gaudriault, S., Ramarao, N., Lereclus, D., and Givaudan, A. (2012). How the insect pathogen bacteria Bacillus thuringiensis and Xenorhabdus Photorhabdus occupy their hosts. Curr. Opin. Microbiol. 15, 220-231. doi: 10.1016/j.mib.2012.04.006

Nizet, V. (2006). Antimicrobial peptide resistance mechanisms of human bacterial pathogens. Curr. Issues Mol. Biol. 8, 11-26.

Palumbo, E., Deghorain, M., Cocconcelli, P. S., Kleerebezem, M., Geyer, A., Hartung, T., et al. (2006). D-Alanyl ester depletion of teichoic acids in Lactobacillus plantarum results in a major modification of lipoteichoic acid composition and cell wall perforations at the septum mediated by the Acm 2 autolysin. J. Bacteriol. 188, 3709-3715. doi: 10.1128/JB.188.10.3709-3715.2006

Pandin, C., Caroff, M., and Condemine, G. (2016). Antimicrobial peptide resistance genes in the plant pathogen Dickeya dadantii. Appl. Environ. Microbiol. 82, 6423-6430.

Perego, M., Glaser, P., Minutello, A., Strauch, M. A., Leopold, K., and Fischer, W. (1995). Incorporation of D-alanine into lipoteichoic acid and wall teichoic acid in Bacillus subtilis identification of genes and regulation. J. Biol. Chem. 270, 15598-15606. doi: 10.1074/jbc.270.26.15598

Peschel, A. (2002). How do bacteria resist human antimicrobial peptides? Trends Microbiol. 10, 179-186. doi: 10.1016/S0966-842X(02)02333-8

Peschel, A., Otto, M., Jack, R. W., Kalbacher, H., Jung, G., and Götz, F. (1999). Inactivation of the dlt operon in Staphylococcus aureus confers sensitivity to defensins, protegrins, and other antimicrobial peptides. J. Biol. Chem. 274, 8405-8410. doi: 10.1074/jbc.274.13.8405

Peschel, A., Vuong, C., Otto, M., and Götz, F. (2000). The D-alanine residues of Staphylococcus aureus teichoic acids alter the susceptibility to vancomycin and the activity of autolytic enzymes. Antimicrob. Agents Chemother. 44, 2845-2847. doi: 10.1128/AAC.44.10.2845-2847.2000

Poyart, C., Pellegrini, E., Marceau, M., Baptista, M., Jaubert, F., Lamy, M. C., et al. (2003). Attenuated virulence of Streptococcus agalactiae deficient in D-alanyl-lipoteichoic acid is due to an increased susceptibility to defensins and phagocytic cells. Mol. Microbiol. 49, 1615-1625. doi: 10.1046/j.1365-2958.2003. 03655.x

Reichmann, N. T., Cassona, C. P., and Gründling, A. (2013). Revised mechanism of d-alanine incorporation into cell wall polymers in Gram-positive bacteria. Microbiology 159, 1868-1877. doi: 10.1099/mic.0.069898-0

Reichmann, N. T., and Gründling, A. (2011). Location, synthesis and function of glycolipids and polyglycerolphosphate lipoteichoic acid in Gram-positive bacteria of the phylum Firmicutes. FEMS Microbiol. Lett. 319, 97-105. doi: 10.1111/j.1574-6968.2011.02260.x

Réjasse, A., Gilois, N., Barbosa, I., Huillet, E., Bevilacqua, C., Tran, S., et al. (2012). Temperature-dependent production of various PlcR-controlled virulence factors in Bacillus weihenstephanensis strain KBAB4. Appl. Environ. Microbiol. 78, 2553-2561. doi: 10.1128/AEM.07446-11

Rutschmann, S., Jung, A. C., Zhou, R., Silverman, N., Hoffmann, J. A., and Ferrandon, D. (2000). Role of Drosophila IKKy in a Toll-independent antibacterial immune response. Nat. Immunol. 1, 342-347. doi: 10.1038/79801 
Schneewind, O., and Missiakas, D. (2014). Lipoteichoic acids, phosphate containing polymers in the envelope of Gram-positive bacteria. J. Bacteriol. 196, 1133-1142. doi: 10.1128/JB.01155-13

Vélez, M. P., Verhoeven, T. L., Draing, C., Von Aulock, S., Pfitzenmaier, M., Geyer, A., et al. (2007). Functional analysis of D-alanylation of lipoteichoic acid in the probiotic strain Lactobacillus rhamnosus GG. Appl. Environ. Microbiol. 73, 3595-3604. doi: 10.1128/AEM. 02083-06

Vollmer, W., Blanot, D., and de Pedro, M. A. (2008). Peptidoglycan structure and architecture. FEMS Microbiol. Rev. 32, 149-167. doi: 10.1111/j.1574-6976.2007. 00094.x

Wang, L., Trawick, J. D., Yamamoto, R., and Zamudio, C. (2004). Genome-wide operon prediction in Staphylococcus aureus. Nucleic Acids Res. 32, 3689-3702. doi: 10.1093/nar/gkh694

Weidenmaier, C., and Peschel, A. (2008). Teichoic acids and related cell-wall glycopolymers in Gram-positive physiology and host interactions. Nat. Rev. Microbiol. 6, 276-287. doi: 10.1038/nrmicro 1861
Xia, G., Kohler, T., and Peschel, A. (2010). The wall teichoic acid and lipoteichoic acid polymers of Staphylococcus aureus. Int. J. Med. Microbiol. 300, 148-154. doi: 10.1016/j.ijmm.2009.10.001

Yount, N. Y., and Yeaman, M. R. (2013). Peptide antimicrobials: cell wall as a bacterial target. Ann. N. Y Acad. Sci. 1277, 127-138. doi: 10.1111/nyas.12005

Conflict of Interest Statement: The authors declare that the research was conducted in the absence of any commercial or financial relationships that could be construed as a potential conflict of interest.

Copyright (c) 2017 Kamar, Réjasse, Jéhanno, Attieh, Courtin, Chapot-Chartier, Nielsen-Leroux, Lereclus, el Chamy, Kallassy and Sanchis-Borja. This is an openaccess article distributed under the terms of the Creative Commons Attribution License (CC BY). The use, distribution or reproduction in other forums is permitted, provided the original author(s) or licensor are credited and that the original publication in this journal is cited, in accordance with accepted academic practice. No use, distribution or reproduction is permitted which does not comply with these terms. 